\title{
Erosive acute colitis associated with intestinal spirochetosis
}

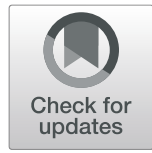

\author{
Fabio Dantas de Paula', Glicia Estevam de Abreu², Maiara Ferreira de Souza ${ }^{3,4}$, \\ Luiz Antonio Rodrigues de Freitas ${ }^{3,4}$ and Daniel Abensur Athanazio ${ }^{3,4^{*}}$ (D)
}

\begin{abstract}
Background: Although usually believed to be harmless, intestinal spirochetosis may active erosive colitis associated with intestinal spirochetosis that may mimic idiopathic chronic inflammatory bowel disease. Case presentation. A 49-year-old homosexual male patient sought medical assistance due to asthenia, rectal bleeding, tenesmus, and diarrhea for one month. He had been using corticosteroids for nine months to treat sciatic nerve pain. Colonoscopy showed rectum and distal sigmoid with diffuse erythema with many surface erosions. Rectal biopsy showed inflammatory changes including chronic changes such as architectural distortion and basal plasmacytosis, and active inflammation including crypt microabscesses. In all large bowel sample, dense colonization of intestinal spirochetosis was observed. Patient also had a positive PCR testing for Chlamydia trachomatis. The patient was treated with metronidazole for 14 days, ciprofloxacin for 14 days and azithromycin (single dose). Symptoms improved and the patient is asymptomatic after two months of follow-up.

Conclusion: In some high-risk groups, intestinal spirochetosis may cause colonic manifestations with overlapping features with intestinal bowel diseases. Awareness of this association is importance since proper antibiotic therapy against Brachyspira (metronidazole) is highly effective. Coinfection with other sexually transmitted infections is common and proper treatment is required.
\end{abstract}

Keywords: Spirochaetales, Colitis, Ulcer

\section{Background}

Intestinal spirochetosis is characterized by the presence of spirochetes (spirally shaped microorganisms) on the luminal surface of the large bowel mucosa. In western countries, its prevalence in biopsies is $2-16 \%$ and is significantly higher in homosexual men and HIV infected patients (up to 50\%). Associations with diverticular disease, intestinal bowel disease, hyperplastic and adenomatous polyps have been described. Most common organisms implicated in intestinal spirochetosis are Brachyspira aalborgi and Brachyspira pilosicoli and are not genetically related to Treponema

\footnotetext{
* Correspondence: dathanazio@gmail.com

${ }^{3}$ Imagepat, Laboratory of Pathology Edf. Eventus Empresarial, 3 Andar Rua Lucaia, 209 Rio Vermelho, Salvador, BA CEP 41940-660, Brazil

${ }^{4}$ Hospital Universitário Professor Edgard Santos / Federal University of Bahia, Salvador, Bahia, Brazil

Full list of author information is available at the end of the article
}

pallidum. The colonization of luminal border of the colonic mucosa is usually not associated with endoscopic abnormalities or inflammatory changes at microscopy (occasional cryptitis may be seen) (Odze and Goldblum, 2014). The organisms stain with WarthinStarry, silver impregnation, Alcian blue $(\mathrm{pH} 2.5)$ and PAS stains, however, some of are subjected to technical quality variations and significant background staining. Specific anti- Brachyspira immunohistochemistry, polymerase chain reaction and in situ hybridization have been developed but are not widely available. A useful supplementary diagnostic tool is the cross reactivity between anti-Treponema using in immunohistochemistry and the microorganisms that cause intestinal spirochetes (Tanahashi et al. 2008; Graham et al. 2018).

(c) The Author(s). 2021 Open Access This article is licensed under a Creative Commons Attribution 4.0 International License, which permits use, sharing, adaptation, distribution and reproduction in any medium or format, as long as you give appropriate credit to the original author(s) and the source, provide a link to the Creative Commons licence, and indicate if changes were made. The images or other third party material in this article are included in the article's Creative Commons licence, unless indicated otherwise in a credit line to the material. If material is not included in the article's Creative Commons licence and your intended use is not permitted by statutory regulation or exceeds the permitted use, you will need to obtain permission directly from the copyright holder. To view a copy of this licence, visit http://creativecommons.org/licenses/by/4.0/. 


\section{Case presentation}

A 49-year-old homosexual male patient sought medical assistance due to asthenia, rectal bleeding, tenesmus, and diarrhea for one month. He had been using corticosteroids (oral and intramuscular) and gabapentin for nine months to treat sciatic nerve pain. He had a prior history of syphilis treatment three years before. Colonoscopy showed rectum and distal sigmoid with diffuse erythema (moderate to severe) with many surface erosions (Fig. 1). Colonic segments and terminal ileum were normal.

Rectal biopsy showed inflammatory changes including basal plasmacytosis, and active inflammation including crypt microabscesses (Fig. 2). In all large bowel samples (cecum, ascendant, transverse, sigmoid and rectum), a dense basophilic surface of spirally shaped organisms was observed. These organisms stained strongly positive for PAS stain and anti-Treponema antibody by immunohistochemistry (Fig. 3).

Serology was negative for CMV, HIV, herpes virus. Serology for syphilis (low VDRL titers) were consistent with past infection. PCR for Chlamydia trachomatis was positive in an anal sample (cobas ${ }^{\circ} 4800$ CT/NG Test, Roche). The patient was treated with metronidazole for 14 days, ciprofloxacin for 14 days and azithromycin (single dose). Symptoms improved
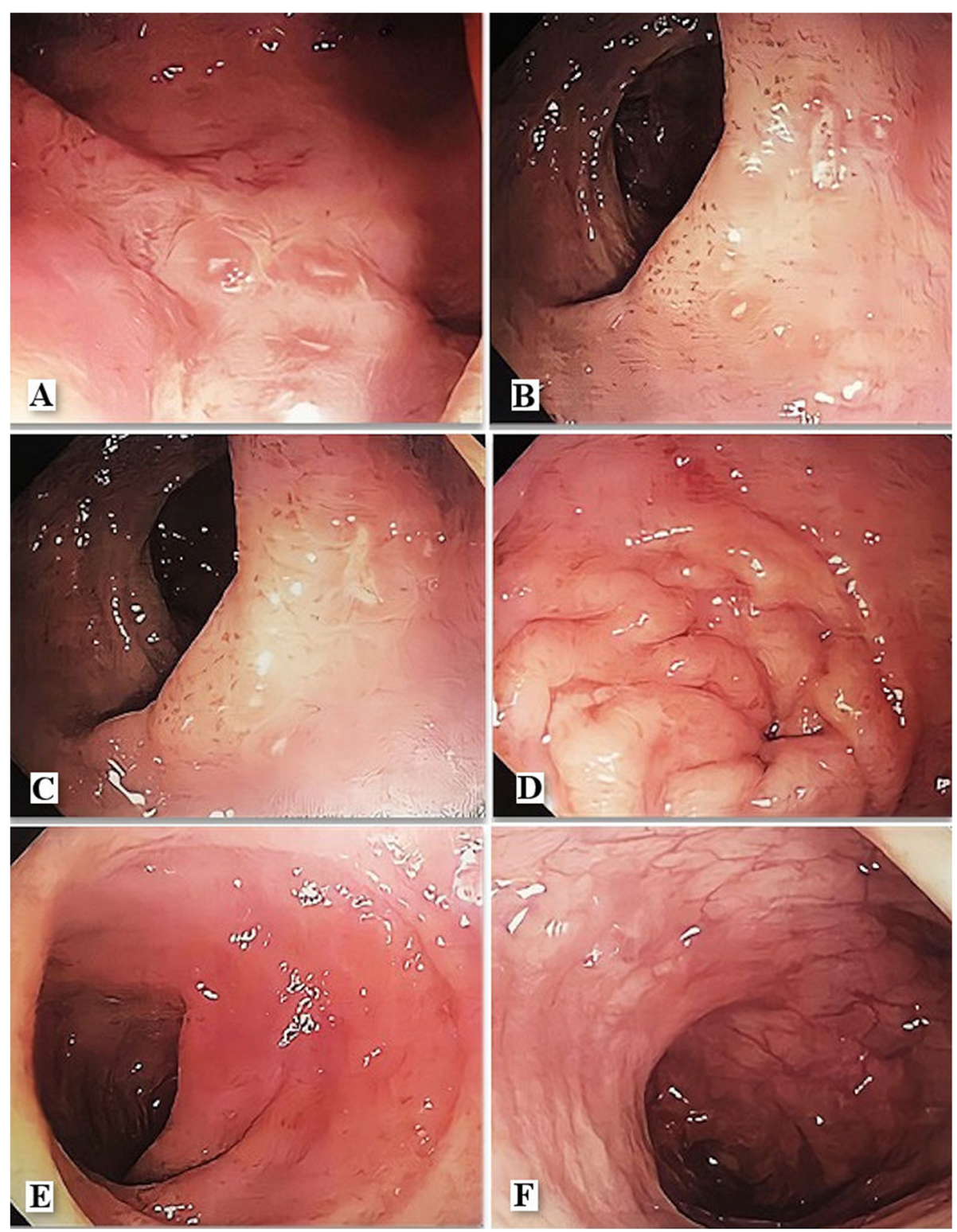

Fig. 1 Colonoscopy. Erosions in rectal mucosa $(A, B, C)$, edema in distal sigmoid (D) mucosal erythema in distal sigmoid (E) and normal sigmoid mucosa (F) 


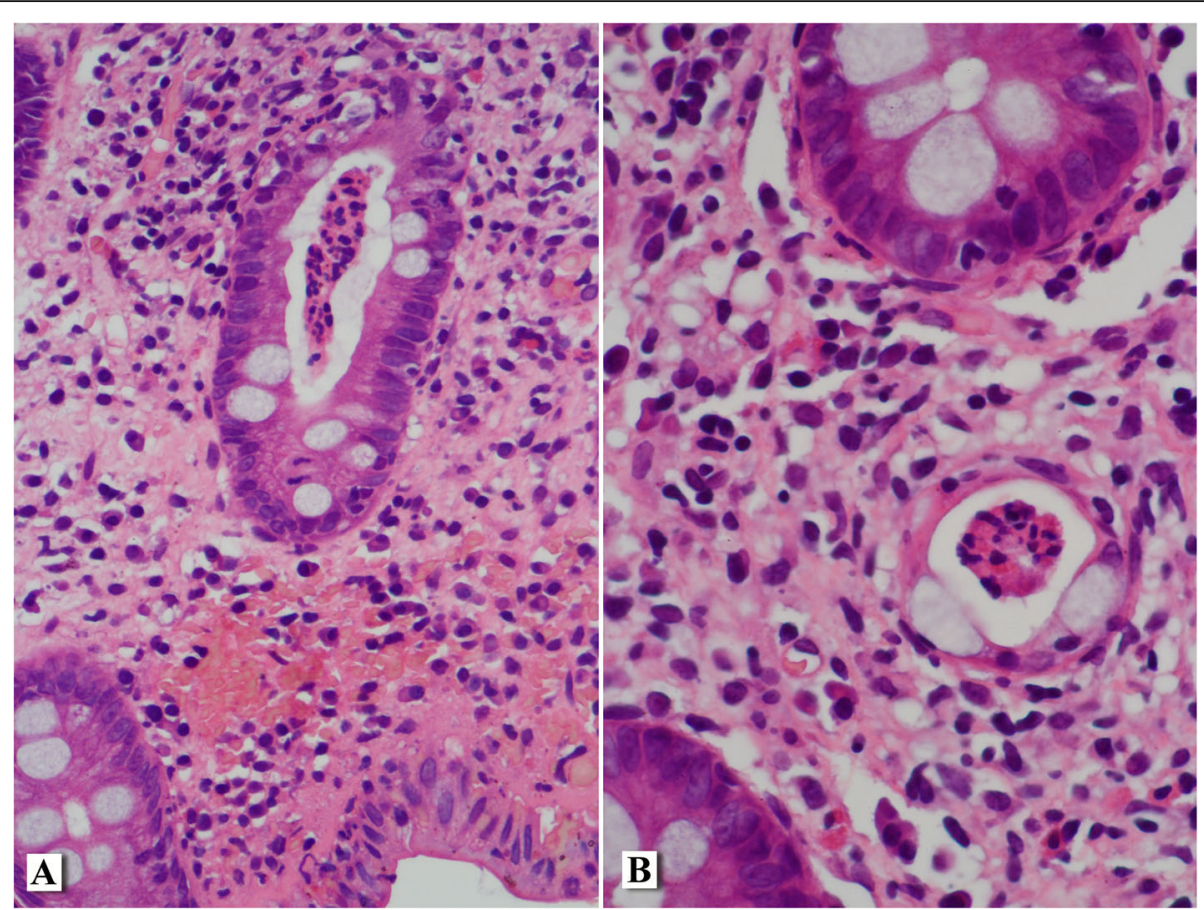

Fig. 2 Rectal biopsy showed inflammatory changes - photomicrographs showing crypt microabscesses. A (100x) and B(400x), HE stain

and the patient is asymptomatic after two months of follow-up.

\section{Discussion}

Although usually believed to be harmless, intestinal spirochetosis has been associated in a case control study with watery diarrhea, change in bowel habits (Alsaigh and Fogt 2002). Most infections are asymptomatic (Tanahashi et al. 2008).

Some recent reports highlight the potential association between intestinal spirochetes and active colitis and mucosal erosions. Agrawal and colleagues reported a 45year-old HIV-positive men with clinical history of one month of constipation, abdominal pain, and intermittent rectal bleeding. Colonoscopy showed aphthous ulcers in rectosigmoid and cecum. The patient had history of syphilis, chlamydia infection and contact with dogs. Symptoms completely resolved after treatment with metronidazole $500 \mathrm{mg} 4$ times a day for 10 days (Agrawal et al. 2019). Other recent publication reports a 38year-old man with recent diagnosis of HIV infection. He had clinical history of fatigue, palpitations, and dyspnea for six months. He had severe anemia and tachycardic. After episodes of rectal bleeding, colonoscopy was performed and revealed fissure, severe colitis with pseudopolyposis, deep ulcerations, erythema, and friability from the anal verge to $17 \mathrm{~cm}$. Magnetic resonance imaging showed perirectal lymphadenopathy and perianal fissures. Treatment was started with steroids due to presumed Crohn's disease. No history or testing for chlamydia was reported. After the pathology report of intestinal spirochetosis involving proximal to sigmoid colon, the patient was treated with metronidazole 500 mg 3 times daily for 10 days and antiretroviral therapy. Symptoms improved within 4 days and resolved in two weeks (Vipani and Yang 2019).

In the patient presented herein, it is not possible to exclude that the main etiologic factor for the mucosal damage was chlamydial infection, or a synergic association of both infections. Chlamydia trachomatis (serovars $\mathrm{D}-\mathrm{K}$ ) is usually a cause of mild proctitis associated with pruritus, mucoid discharge, and perianal pain. Two thirds of all infections are asymptomatic (Hamlyn and Taylor 2006). Serotypes L1, L2, and L3 causes lymphogranuloma venereum which may be associated with severe proctitis, rectal ulcerations, purulent or sanguineous anal discharge (Hamlyn and Taylor 2006). Patients may also present with perirectal abscesses, anal fissures, fistula formation and chronic diarrhea - thus simulating Crohn's disease (Assi et al. 2014). The patient had no significant lymphadenopathy at time of presentation. The PCR test comprises the L1, L2 and L3 serotypes. The successful treatment, however, was not the recommended regimen for lymphogranuloma venereum (21 days of doxycycline, azithromycin, and erythromycin). There is no serologic testing established and starboarded for lymphogranuloma venereum (Center of Disease Control and Prevention, USA, 2021). 


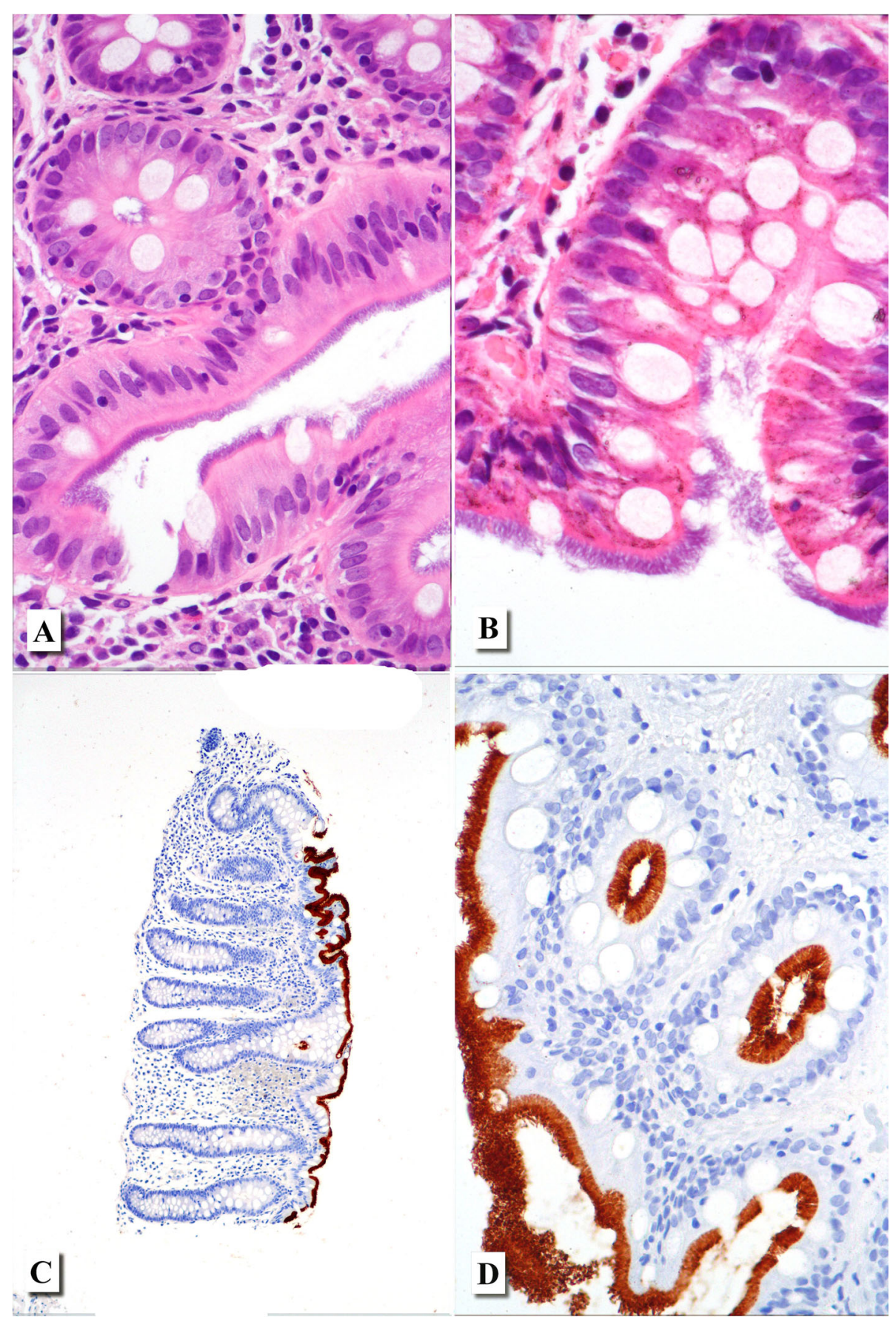

Fig. 3 Photomicrographs of the transverse colon illustrating a dense basophilic surface of spirally shaped organisms seen in all large bowel samples. HE(A: 100x and B:400 magnification) and immunohistochemistry anti-Treponema (C: 40x and D: 100x)

In the present case, we did not observe increased intramucosal eosinophils (in lamina propria or intraepithelial) in any biopsy samples. Some recent studies highlighted these findings as commonly associated with intestinal spirochetosis (Walker et al. 2015; Ogata et al. 2021).

\section{Conclusion}

In some high-risk groups, notably homosexual men and HIV positive patients, intestinal spirochetosis may cause colonic manifestations with overlapping features with intestinal bowel diseases. Awareness of this association is importance since proper antibiotic therapy against 
Brachyspira (metronidazole) is highly effective. Coinfection with other sexually transmitted infections is common and proper treatment is required.

\section{Abbreviations}

HE: Hematoxylin and eosin stain

\section{Acknowledgements}

None.

\section{Authors' contributions}

FDP, GEA and DAA conceived the idea. FDP, DAA and GEA was the major contributor to the writing of the manuscript. DDA, MFS and LFRA diagnosed the cases. MSF, and LARF were major contributors for critically revising the manuscript for important intellectual content. The authors read and approved the final manuscript.

\section{Funding}

This work has no funding sources.

\section{Availability of data and materials}

Supplementary data is available upon request.

Ethics approval and consent to participate

Ethics approval: not applicable.

Written informed consent was obtained from the patient for participation in this case report. A copy of the written consent is available for review by the Editor-in-Chief of this journal.

\section{Consent for publication}

Written informed consent was obtained from the patient for publication of this case report and any accompanying images. A copy of the written consent is available for review by the Editor-in-Chief of this journal.

\section{Competing interests}

The authors declare that they have no competing interests.

\section{Author details}

${ }^{1}$ Hospital de Endoscopia Ramiro Mascarenhas, Salvador, Bahia, Brazil. ${ }^{2}$ Hospital Aliança, Salvador, Bahia, Brazil. ${ }^{3}$ Imagepat, Laboratory of Pathology Edf. Eventus Empresarial, 3 Andar Rua Lucaia, 209 Rio Vermelho, Salvador, BA CEP 41940-660, Brazil. ${ }^{4}$ Hospital Universitário Professor Edgard Santos /

Federal University of Bahia, Salvador, Bahia, Brazil.

Received: 8 September 2021 Accepted: 9 October 2021

Published online: 11 December 2021

\section{References}

Agrawal M, Zhang W, Lukin D. Intestinal Spirochetosis resembles inflammatory bowel disease in a patient with HIV infection. Clin Gastroenterol Hepatol. 2019;17(6):e60. https://doi.org/10.1016/j.cgh.2018.05.055.

Alsaigh N, Fogt F. Intestinal spirochetosis: clinicopathological features with review of the literature. Color Dis. 2002;4(2):97-100. https://doi.org/10.1046/j.14 63-1318.2002.00284.x.

Assi R, Hashim PW, Reddy VB, Einarsdottir H, Longo WE. Sexually transmitted infections of the anus and rectum. World J Gastroenterol. 2014;20(41):152628. https://doi.org/10.3748/wjg.v20.141.15262.

Center of Disease Control and Prevention. Lymphogranuloma Venereum. In: Sexually Transmitted Infections Treatment Guidelines. 2021:2021 https:// www.cdc.gov/std/treatment-guidelines/lgv.htm.

Graham RP, Naini BV, Shah SS, Arnold CA, Kannangai R, Torbenson MS, LamHimlin DM. Treponema pallidum immunohistochemistry is positive in human intestinal Spirochetosis. Diagn Pathol. 2018;13(1):7. https://doi.org/10.1186/ s13000-017-0676-6.

Hamlyn E, Taylor C. Sexually transmitted proctitis. Postgrad Med J. 2006;82(973): 733-6. https://doi.org/10.1136/pmj.2006.048488.

Odze RD, Goldblum JR. Surgical pathology of the Gastointestinal, liver, biliary tract and pancreas. Philadelphia: Elsevier Saunders; 2014. p. 72-3.

Ogata S, Shimizu K, Tominaga S, Matsukuma S. Mucosal eosinophilic infiltration may be a characteristic of human intestinal spirochetosis. BMC Infect Dis. 2021;21(1):721. https://doi.org/10.1186/s12879-021-06418-8.
Tanahashi J, Daa T, Gamachi A, Kashima K, Kondoh Y, Yada N, Yokoyama S. Human intestinal spirochetosis in Japan; its incidence, clinicopathologic features, and genotypic identification. Mod Pathol. 2008;21(2):76-84. https:// doi.org/10.1038/modpathol.3800987.

Vipani A, Yang MX. Intestinal Spirochetosis masquerading as inflammatory bowel disease. Am J Med. 2019;132(8):e654-5. https://doi.org/10.1016/j.amjmed.201 9.03.013.

Walker MM, Talley NJ, Inganäs L, Engstrand L, Jones MP, Nyhlin H, Agréus L, Kjellstrom L, Öst Å, Andreasson A. Colonic spirochetosis is associated with colonic eosinophilia and irritable bowel syndrome in a general population in Sweden. Hum Pathol. 2015;46(2):277-83. https://doi.org/10.1016/j.humpath.2 014.10 .026

\section{Publisher's Note}

Springer Nature remains neutral with regard to jurisdictional claims in published maps and institutional affiliations.
Ready to submit your research? Choose BMC and benefit from:

- fast, convenient online submission

- thorough peer review by experienced researchers in your field

- rapid publication on acceptance

- support for research data, including large and complex data types

- gold Open Access which fosters wider collaboration and increased citations

- maximum visibility for your research: over $100 \mathrm{M}$ website views per year

At $\mathrm{BMC}$, research is always in progress.

Learn more biomedcentral.com/submissions 